\title{
Reduced environmental stimuli is associated with improved insulin-like growth factor-1 levels and physical growth in very low birth weight premature infants
}

\author{
YUE-FENG CHEN ${ }^{1}, \mathrm{CHUN}$ WANG LIN ${ }^{2}$, JIN-FENG ZHANG $^{3}, \mathrm{MIN} \mathrm{LU}^{1},{\text { YANFENG } \mathrm{LI}^{3} \text { and YANBIN YU }}^{1}$ \\ Departments of ${ }^{1}$ Nursing, ${ }^{2}$ Pediatrics and ${ }^{3}$ Neonates, Shunde Women and Children's Hospital, \\ Shunde, Guangdong 528300, P.R. China
}

Received October 24, 2018; Accepted March 1, 2019

DOI: $10.3892 /$ etm.2019.7489

\begin{abstract}
Standard environmental features of the neonatal intensive care unit (NICU) may be stressful and not optimal for the maturation of very low birth weight premature infants (VLBWPIs). The present study investigated whether structured no-touch periods and reducing periods of light and sound stimulation may influence the developmental indices of VLBWPIs. Between June 2012 and June 2013, 60 consecutive VLBWPIs were equally apportioned to either an experimental or control group. The groups were statistically comparable with regard to sex ratio, gestational age and birth weight. Each group received routine nursing care, but infants in the experimental group were additionally cared for in a separate room with $3 \mathrm{~h}$ of rest every $8 \mathrm{~h}$, and reduced light and sound from staff and instruments. At 7 and 14 days following birth, plasma insulin-like growth factor 1 (IGF-1) levels of the experimental group were significantly higher than that of the control group. Furthermore, at day 7 and 14, the body weight and crown-to-heel lengths were significantly increased in the experimental group compared with the control group. In summary, during the first 2 weeks following birth, the reduction of touch, sound and light stimulation in the NICU were associated with higher plasma IGF-1 levels and physical growth of VLBWPIs. These results may have implications for the better management of VLBWPIs in the NICU.
\end{abstract}

\section{Introduction}

Very low birth weight premature infants (VLBWPIs) are cared for in the neonatal intensive care unit (NICU), which

Correspondence to: Dr Chun-Wang Lin, Department of Pediatrics, Shunde Women and Children's Hospital, 3 Baojian Street, Shunde, Guangdong 528300, P.R. China

E-mail: chunwanglin@126.com

Key words: very low birth weight premature infants, neonatal intensive care unit, insulin-like growth factor-1, physical growth must meet the requirements of a restful and a stress-free environment (1). It has been reported that during the first 2 weeks following birth, touch, sound and light stimulation in the NICU are positively associated with median diastolic blood pressure, mean arterial pressure and infant movement $(2,3)$.

Growth hormones directly promote bone growth and increase height (1). Insulin-like growth factor 1 (IGF-1) is a single-stranded polypeptide that is regulated by growth hormones. Thus, circulating IGF-1 levels may indicate the activity of growth hormones and the progress of maturation in VLBWPIs (1,4). Previous studies have revealed that IGF-1 is essential for postnatal growth and development in humans (5), and that low levels of IGF-1 may be involved in the prolonged growth restriction of VLBWPIs (6).

It is logical to assume that stressful environmental features may affect the maturation of VLBWPIs and will thus affect their IGF-1 levels $(3,4)$. However, the specific environmental features that affect circulating IGF-1 levels of VLBWPIs remains unclear. The current study hypothesized that if stimuli in the NICU are reduced and benign circadian rules are established, then IGF-1 levels will increase and VLBWPIs will adapt more easily to the environment outside the womb, increasing their physiological wellbeing.

The present study assessed associations between the environmental characteristics of the NICU and VLBWPI plasma IGF-1 levels and growth indices.

\section{Materials and methods}

Subjects. Subjects were recruited between June 2012 and June 2013 at Shunde Women's and Children's Hospital (Shunde, China). A total of 60 VLBWPIs were consecutively enrolled and apportioned to either an experimental or control group (each, $n=30$ ). All the VLBWPIs conformed to the following criteria: Birth weight $<1,500 \mathrm{~g}$; gestational age $<37$ weeks; and hospitalization $\geq 14$ days. The following potential subjects were excluded: Patients with a history of asphyxia at birth with congenital malformations or genetic metabolic diseases; and cases of mortality. The experimental group comprised 18 males and 12 females, with a gestational age of $30.62 \pm 2.22$ weeks, a body mass 
Table I. Development indices on day 7 and 14 following birth in the experimental and control groups.

\begin{tabular}{|c|c|c|c|c|}
\hline & Experimental & Control & $\mathrm{t}$-value & P-value \\
\hline Gender ratio $(\mathrm{M} / \mathrm{F})$ & $18 / 12$ & $16 / 14$ & 1.15 & 0.216 \\
\hline \multicolumn{5}{|l|}{ At birth } \\
\hline GA (weeks) & $30.62 \pm 2.22$ & $30.54 \pm 2.58$ & 0.48 & 0.531 \\
\hline $\mathrm{BW}(\mathrm{kg})$ & $1.18 \pm 0.19$ & $1.21 \pm 0.19$ & 0.95 & 0.268 \\
\hline $\mathrm{C}-\mathrm{H}(\mathrm{cm})$ & $39.87 \pm 2.07$ & $39.02 \pm 2.13$ & 0.58 & 0.425 \\
\hline $\mathrm{HC}(\mathrm{cm})$ & $27.96 \pm 0.96$ & $27.22 \pm 0.95$ & 0.65 & 0.403 \\
\hline \multicolumn{5}{|l|}{7 days after birth } \\
\hline BW (kg) & $1.47 \pm 0.15$ & $1.23 \pm 0.14$ & 2.74 & 0.039 \\
\hline C-H (cm) & $41.58 \pm 2.55$ & $39.15 \pm 2.35$ & 2.66 & 0.045 \\
\hline $\mathrm{HC}(\mathrm{cm})$ & $28.83 \pm 1.05$ & $27.61 \pm 0.98$ & 2.67 & 0.078 \\
\hline \multicolumn{5}{|l|}{14 days after birth } \\
\hline BW (kg) & $1.68 \pm 0.17$ & $1.37 \pm 0.17$ & 3.08 & 0.028 \\
\hline C-H (cm) & $42.84 \pm 2.73$ & $39.61 \pm 2.57$ & 2.69 & 0.042 \\
\hline $\mathrm{HC}(\mathrm{cm})$ & $29.84 \pm 1.13$ & $28.62 \pm 1.07$ & 1.51 & 0.079 \\
\hline
\end{tabular}

GA, gestational age; BW, body weight; C-H, crown-to-heel length; $\mathrm{HC}$, head circumference.

of $1.18 \pm 0.19 \mathrm{~kg}$, a crown-to-heel length of $39.87 \pm 2.07 \mathrm{~cm}$ and a head circumference of $27.96 \pm 0.96 \mathrm{~cm}$ (Table I). The control group consisted of 16 males and 14 females, with a gestational age of $30.54 \pm 2.58$ weeks, a body mass of $1.21 \pm 0.19 \mathrm{~kg}$, a crown-to-heel length of $39.02 \pm 2.13 \mathrm{~cm}$ and a head circumference $27.22 \pm 0.95 \mathrm{~cm}$. Differences in sex ratio, gestational age, body mass, crown-to-heel length and head circumference between the groups were not statistically significant at birth.

Standard nursing care of VLBWPIs. Patients in the control group received routine standard nursing care for VLBWPIs. Patients in the experimental group also received routine standard nursing care for VLBWPIs, however they were placed in a separate room under the following conditions: A quiet period of $3 \mathrm{~h}$ every $8 \mathrm{~h}$ was maintained, in which patients were not touched unless there was a need for treatment. Light stimulation was reduced by drawing the curtains, using brunet cloth covers over warmers, dimming the indoor lights and using a dim bedside lamp at night. Noise was reduced by enabling phone flash caller ids on all phones, reducing the volume of all instrument alarms and sounds made by the medical staff to $<50 \mathrm{dBA}$, and limiting impulse noise from the heart rate, breathing and blood pressure monitors to $<55$ dBA (7). Simultaneously, regular visits were conducted by the nurses to ensure timely responses to instrument alarms. Patients in the experimental and control groups, as well as all instruments were positioned within the field of vision of the nurses station for easy observation and to prevent accidents. This prospective, double-blinded, sequential-period, exploratory study was approved by the Ethics Committee of Shunde Women's and Children's Hospital (Shunde, China). All parents or guardians of the children enrolled in the present study provided written informed consent prior to enrollment.
Laboratory assays. VLBWPI plasma IGF-1 levels were measured. Venous blood samples $(2 \mathrm{ml})$ were collected and plasma IGF-1 concentrations were measured using a fully automated chemical luminescence immunity analyzer (Siemens Healthineers, Erlangen, Germany; Model, IMMULITE 2000).

Statistical analysis. Data are presented as the mean \pm standard deviation. Statistical analyses were performed using SPSS statistical software (version 17.0; SPSS, Inc., Chicago, IL, USA). Figures were generated using GraphPad software (version 4.0; GraphPad Software, Inc., La Jolla, CA, USA). Continuous variables were tested using an independent sample t-test. $\mathrm{P}<0.05$ was considered to indicate a statistically significant difference.

\section{Results}

Effects of reduced environmental stimulation on plasma IGF-1 levels. The plasma IGF-1 levels of the VLBWPIs in the experimental group at day $7(40.71 \pm 21.04 \mu \mathrm{g} / \mathrm{l})$ and day $14(50.63 \pm 19.79 \mu \mathrm{g} / \mathrm{l})$ were significantly higher than that of the control group (day 7, 24.7 $\pm 11.62 \mu \mathrm{g} / \mathrm{l}$; day 14 , $28.88 \pm 14.50 \mu \mathrm{g} / \mathrm{l})$ following birth $(\mathrm{t}=3.65$ and 4.86 , respectively; $\mathrm{P}<0.01$; Fig. 1).

Effects of reduced environmental stimulation on body weight, crown-to-heel length and head circumference. On day 7 and 14 following birth, VLBWPIs in the experimental group exhibited significantly increased body weight and crown-to-heel length compared with the VLBWPIs in the control group $(\mathrm{P}<0.05$; Table I). In addition, VLBWPIs in the experimental group exhibited increased head circumference compared with the VLBWPIs of the control group, however there was no significant difference observed $(P>0.05$; Table I). 

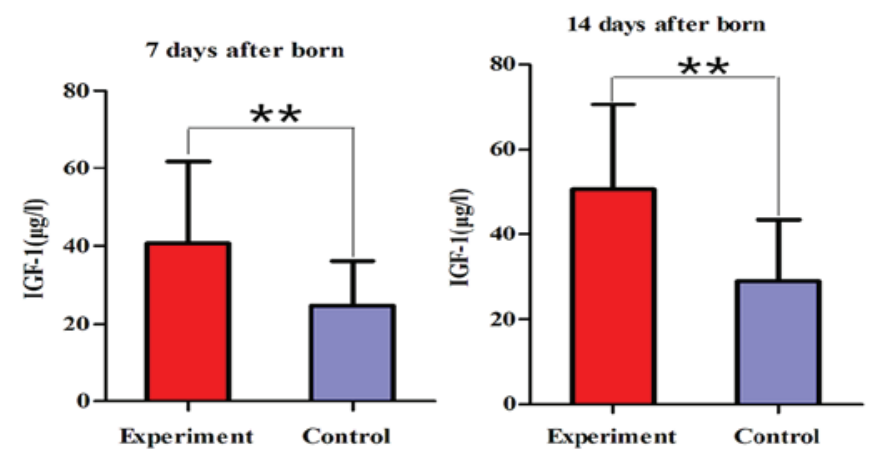

Figure 1. Plasma IGF-1 levels on day 7 and 14 following birth in the experimental and control groups. ${ }^{* *} \mathrm{P}<0.01$ vs. Control. IGF-1, insulin-like growth factor 1 .

\section{Discussion}

The present study assessed whether reducing the stress of touch, sound and light in the NICU promotes plasma IGF-1 levels and the physical growth of VLBWPIs. A total of 60 VLBWPIs were treated with routine nursing care in the NICU, but 30 of these infants (the experimental group) were placed in a separate room with reduced stimulations from touch, sound and light. The results revealed that on day 7 and 14 following birth, the experimental group exhibited significantly increased levels of plasma IGF-1, body weight and crown-to-heel lengths compared with the control group.

IGF-1 is a single-stranded polypeptide regulated by growth hormones that indicates the activity of growth hormones that directly promotes bone growth and height $(1,8)$. Plasma IGF-1 concentrations are considered to be an index of nutritional status in the fetus and preterm infants (9). There is a high risk of low birth weight when fetal plasma IGF-1 concentrations are continuously low and the rate of growth hormone conversion to IGF-1 will significantly influence stature throughout childhood (5,9-11).

In the present study, the difference in plasma IGF-1 concentrations between the experimental and control group on day 7 and 14 following birth were statistically significant, as were the indices of development. Vatten et al (12) demonstrated that levels of IGF-I contributed positively to birth weight and length, and high levels of IGF-I were associated with low birth weight and reduced length, which is consistent with the results of the present study. Compared with full term infants, VLBWPIs are less able to adjust to external stimuli. VLBWPIs are often disturbed and awakened by sounds in the NICU, which results in sleeping disorders, a higher consumption of energy and reduced body growth (1). Most noises in the NICU are due to activities of the medical staff, instruments and alarms $(1,2,4)$.

In the present study, plasma IGF-1 levels of VLBWPIs on day 7 and 14 following birth were significantly higher in the experimental group than in the control group, and the body weight and crown-to-heel length were also significantly higher in the experimental group. The results of the present study indicate that circulating IGF-1 in VLBWPIs is negatively associated with stimulations in their environment. Specifically, the beneficial effects of IGF-1 may be promoted by reducing exposure to unnecessary light, limiting continuous noise to $<50 \mathrm{dBA}$, impulse noise to $<55 \mathrm{dBA}$ and providing care that allows for an undisturbed sleep (4).

In summary, interventions in living conditions should be implemented as soon as possible following birth, to allow VLBWPIs to adapt more easily to the environment outside the womb. This includes establishing benign circadian rules that enable infants to stimulate the secretion of IGF-1, which in turn promotes the growth of bones and body mass $(1,8,13)$. A previous study has corroborated that noise from the NICU can lead to negative physiological effects for VLBWPIs, including a lower breathing rate, heart rate and blood oxygen saturation, all of which may threaten the survival of infants (14). Thus, reducing environmental stress due to touch, light and sound in the NICU may promote plasma IGF-1 levels and the physical growth of VLBWPIs.

\section{Acknowledgements}

Not applicable.

\section{Funding}

The present study was supported by grants from the Bureau of Science and Technology of Foshan City in China (grant no. 201208255).

\section{Availability of data and materials}

All datasets used and/or analyzed during the present study are available from the corresponding author on reasonable request.

\section{Authors' contributions}

YC and CL contributed to the conception and design of the study. ML, YL and YY performed the experiments. JZ and YL analyzed the data. YC and CL prepared the manuscript. All authors read and approved the final manuscript.

\section{Ethics approval and consent to participate}

The study was approved by the Ethics Committee of Shunde Women's and Children's Hospital (Shunde, China).

\section{Patient consent for publication}

All parents or guardians of the children enrolled in this study provided written informed consent for publication.

\section{Competing interests}

The authors declare that they have no competing interests.

\section{References}

1. Beardsall K, Vanhaesebrouck S, Frystyk J, Ogilvy-Stuart AL, Vanhole C, van Weissenbruch M, Midgley P, Thio M, Cornette L, Gill B, et al: Relationship between insulin-like growth factor I levels, early insulin treatment, and clinical outcomes of very low birth weight infants. J Pediatr 164: 1038-1044.e1, 2014.

2. Chang YJ, Lin CH and Lin LH: Noise and related events in a neonatal intensive care unit. Acta Paediatr Taiwan 42: 212-217, 2001. 
3. Slevin M, Farrington N, Duffy G, Daly L and Murphy JF: Altering the NICU and measuring infants' responses. Acta Paediatr 89: 577-581, 2000.

4. Kawai N, Kanzaki S, Takano-Watou S, Tada C, Yamanaka Y, Miyata T, Oka M and Seino Y: Serum free insulin-like growth factor I (IGF-I), total IGF-I, and IGF-binding protein-3 concentrations in normal children and children with growth hormone deficiency. J Clin Endocrinol Metab 84: 82-89, 1999.

5. Walenkamp MJ, Losekoot M and Wit JM: Molecular IGF-1 and IGF-1 receptor defects: From genetics to clinical management. Endocr Dev 24: 128-137, 2013.

6. Kwinta P, Klimek M, Wójcik M, Grudzień A, Drozdz D and Pietrzyk JJ: Insulin-like growth factor-1 (IGF-1) serum concentration among 7-year-old extremely low birth weight children-an indicator of growth problems. J Pediatr Endocrinol Metab 24 651-657, 2011.

7. Committeeto Establish Recommended Standards for Newborn ICU Design Recommend Standards for Newborn ICU Design Report of the Fitthconsensus Conferenceon Newborn ICU Design 1, 2002.

8. Radetti G, Bozzola M, Paganini C, Valentini R, Gentili L, Tettoni $\mathrm{K}$ and Tatò L: Growth hormone bioactivity and levels of growth hormone, growth hormone-binding protein, insulinlike growth factor I, and insulinlike growth factor-binding proteins in premature and full-term newborns during the first month of life. Arch Pediatr Adolesc Med 151: 170-175, 1997.

9. Hawkes $\mathrm{CP}$ and Grimberg A: Insulin-like growth factor-I is a marker for the nutritional state. Pediatr Endocrinol Rev 13: 499-511, 2015.
10. Hellström A, Ley D, Hansen-Pupp I, Hallberg B, Löfqvist C, van Marter L, van Weissenbruch M, Ramenghi LA, Beardsall K, Dunger D, et al: Insulin-like growth factor 1 has multisystem effects on foetal and preterm infant development. Acta Paediatr 105: 576-586, 2016.

11. Hellström A, Engström E, Hård AL, Albertsson-Wikland K, Carlsson B, Niklasson A, Löfqvist C, Svensson E, Holm S, Ewald U, et al: Postnatal serum insulin-like growth factor I deficiency is associated with retinopathy of prematurity and other complications of premature birth. Pediatrics 112: 1016-1020, 2003.

12. Vatten LJ, Nilsen ST, Odegård RA, Romundstad PR and Austgulen R: Insulin-like growth factor I and leptin in umbilical cord plasma and infant birth size at term. Pediatrics 109: 1131-1135, 2002

13. Engström E, Niklasson A, Wikland KA, Ewald U and Hellström A: The role of maternal factors, postnatal nutrition, weight gain, and gender in regulation of serum IGF-I among preterm infants. Pediatr Res 57: 605-610, 2005.

14. Tessier R, Cristo M, Velez S, Giron M, de Calume ZF, Ruiz-Palaez JG, Charpak Y and Charpak N: Kangaroo mother care and the bonding hypothesis. Pediatrics 102: e17, 1998. 